Full Title:

Genomic knockout of alms1 in zebrafish recapitulates Alström syndrome and provides insight into metabolic phenotypes

4
Jessica E. Nesmith ${ }^{1}$, Timothy L. Hostelley ${ }^{1}$, Carmen C. Leitch ${ }^{1}$, Maggie S. Matern ${ }^{2}$, Saumil Sethna ${ }^{2}$, Rebecca McFarland $^{1}$, Sukanya Lodh ${ }^{1 \wedge}$, Christopher J. Westlake ${ }^{3}$, Ronna Hertzano ${ }^{2,4,5}$, Zubair M. Ahmed ${ }^{2,6}$, Norann A. Zaghloul ${ }^{1 *}$

${ }^{1}$ Division of Endocrinology, Diabetes and Nutrition, Department of Medicine, University of Maryland School of Medicine, Baltimore, MD USA

${ }^{2}$ Department of Otorhinolaryngology, Head and Neck Surgery, University of Maryland School of Medicine, Baltimore, MD USA

${ }^{3}$ Laboratory of Cell and Developmental Signaling, Membrane Trafficking and Signaling Section, Center for Cancer Research, National Cancer Institute, Frederick, MD USA

${ }^{4}$ Institute for Genome Sciences, University of Maryland School of Medicine, Baltimore, MD USA

${ }^{5}$ Department of Anatomy and Neurobiology, University of Maryland School of Medicine, Baltimore, MD USA

${ }^{6}$ Department of Biochemistry and Molecular Biology, University of Maryland School of Medicine, Baltimore, MD USA

^ Current affiliation: Department of Biological Sciences, Marquette University, Milwaukee, WI USA

* Author for Correspondence:

Norann A. Zaghloul, PhD

Health Sciences Facility III, Room 4176

670 W. Baltimore Street

Baltimore, MD 21201 USA

Telephone: 410-706-1646

Email: zaghloul@umaryland.edu 


\section{SCIENTIFIC ABSTRACT}

42 Alström syndrome is an autosomal recessive obesity ciliopathy caused by loss-of-function

43 mutations in the ALMS1 gene. In addition to multi-organ dysfunction, such as cardiomyopathy,

44 retinal degeneration, and renal dysfunction, the disorder is characterized by high rates of

45 obesity, insulin resistance and early onset type 2 diabetes mellitus (T2DM). To investigate

46 mechanisms linking disease phenotypes we generated a loss-of-function deletion of alms 1 in

47 the zebrafish using CRISPR/Cas9. We demonstrate conserved phenotypic effects including

48 cardiac defects, retinal degeneration, and metabolic deficits that included propensity for obesity

49 and fatty livers in addition to hyperinsulinemia and glucose response defects. Gene expression

50 changes in $\beta$-cells isolated from alms $1^{-/}$mutants revealed changes consistent with insulin

51 hyper-secretion and glucose sensing failure, which were also identified in cultured murine $\beta$ -

52 cells lacking Alms1. These data present a zebrafish model to assess etiology and new secretory

53 pathway defects underlying Alström syndrome-associated metabolic phenotypes. Given the

54 hyperinsulinemia and reduced glucose sensitivity in these animals we also propose the alms 1

55 loss-of-function mutant as a monogenic model for studying T2DM phenotypes. 


\section{AUTHOR SUMMARY}

57 These data comprise a thorough characterization of a zebrafish model of Alström syndrome, 58 a human obesity syndrome caused by loss-of-function deletions in a single gene, ALMS1. The

59 high rates of obesity and insulin resistance found in these patients suggest this disorder as a

60 single-gene model for Type 2 Diabetes Mellitus (T2DM), a disorder caused by a variety of

61 environmental and genetic factors in the general population. We identify a propensity for

62 obesity, excess lipid storage, loss of $\beta$-cells in islets, and hyperinsulinemia in larval and adult

63 stages of zebrafish alms 1 mutants. We isolated $\beta$-cells from the alms 1 mutants and compared

64 the gene expression profiles from RNASeq datasets to identify molecular pathways that may

65 contribute to the loss of $\beta$-cells and hyperinsulinemia. The increase in genes implicated in

66 generalized pancreatic secretion, insulin secretion, and glucose transport suggest potential $\beta$ -

67 cell exhaustion as a source of $\beta$-cell loss and excess larval insulin. We propose this mutant as a

68 new genetic tool for understanding the metabolic failures found in Type 2 Diabetes Mellitus. 
Primary cilia are present on the majority of vertebrate cell types and act as cellular hubs for

71 sensing and transducing signaling pathways (1). Deletions in ciliary genes-including basal

72 body proteins, transition zone components, and intraflagellar transport elements —are

73 implicated in a class of diseases termed the ciliopathies which exhibit a broad range of

74 phenotypes (2,3). A unique subset among these disorders are the obesity ciliopathies that

75 present with highly penetrant, early onset obesity. Alström syndrome, one of two major obesity

76 ciliopathies, is associated with the most profound metabolic derangement among the disorders,

77 including prominent truncal obesity, severe insulin resistance, hyperinsulinemia, early onset

78 Type 2 Diabetes Mellitus (T2DM), and several other metabolic syndrome features $(4,5)$. This

79 rare autosomal recessive syndrome is caused by pathogenic variants in ALMS1, which localizes

80 to the basal body of cilia (6), and may play a role in intracellular trafficking $(7,8)$. Additional

81 hallmark features of the disorder include cardiomyopathy, retinal degeneration, and renal

82 dysfunction, as well as childhood obesity and T2DM. The unique features of Alström syndrome,

83 however, offer the opportunity for generating models to better understand the cellular etiology

84 underlying metabolic conditions, including T2DM, and to investigate the potential role of ciliary

85 proteins.

86 Here, we present a zebrafish model of Alström syndrome. Zebrafish (Danio rerio) have long

87 been used as models of human genetic disease. The external embryonic development allows

88 for whole-body knockdown and knockout studies, the wide range of existing transgenic

89 reporters and translucent body plan permits high-resolution microscopy of whole animals, and

90 the high fecundity provides ease of mutant generation as well as large scale -omic studies (9-

91 12). Zebrafish have also recently emerged as robust models of metabolic traits owing to

92 conservation of basic physiology, including gastrointestinal function, endocrine regulation, lipid

93 and glucose metabolism, and central neuronal regulation of food intake, all present by 5 days

94 post-fertilization (dpf) $(13,14)$. We previously demonstrated a link between $\beta$-cell proliferation 
95 and obesity ciliopathies using knockdown models of two ciliopathies, Bardet-Biedl syndrome

96 (BBS) and Alström syndrome (8,15). The latter was carried out by transient knockdown of the

97 zebrafish alms1 gene during early embryonic stages. While these studies inform the role of

98 alms 1 in regulation of $\beta$-cell production early in life, the inherent limitations of transient

99 knockdown preclude more extensive investigation of other later onset and adult phenotypes.

100 In the present study, we generated a genomic model of Alström syndrome by targeting the

101 zebrafish alms1 gene using CRISPR/Cas9. The resulting heritable mutation ablated protein

102 production and resulted in systemic defects that recapitulate the human syndrome and existing

103 mouse models, including defects in neurosensory, cardiac, renal, and metabolic systems. We

104 further explored metabolic phenotypes and found highly penetrant hepatic steatosis, increased

105 weight gain under high fat feeding conditions, impaired glucose uptake, defective $\beta$-cell

106 response to high-glucose conditions, and early onset hyperinsulinemia. To more closely

107 examine glucose regulation in Alström syndrome, we introduced the loss-of-function mutation in

108 alms 1 into a transgenic $\beta$-cell reporter line. We used this line to selectively isolate $\beta$-cells from

109 the alms $1^{-/}$zebrafish and examine whole transcriptome data using RNA-seq. These data

110 support a role for alms 1 in modulation of $\beta$-cell insulin secretion through regulation of

111 intracellular secretion and also provide evidence of impaired $\beta$-cell glucose-sensing. These

112 findings indicate $\beta$-cell autonomous defects are a primary driver of early onset hyperinsulinemia

113 and early onset T2DM, providing insight into $\beta$-cell defects underlying more common forms of

114 T2DM.

115

116 RESULTS

117 Generation of a zebrafish alms1 genomic loss-of-function mutant

118 We targeted zebrafish alms1 with CRISPR/Cas9 by injection of guide RNAs (gRNA)

119 targeted to exon 4 of the gene along with Cas9 protein injection directly into 1-cell stage 
120 embryos (Fig 1A). To allow for both whole body phenotyping as well as $\beta$-cell-specific defects in

121 mutants, we deleted alms1 in the Tg(insa:mCherry) transgenic zebrafish in which $\beta$-cells

122 express the mCherry fluorophore under control of the preproinsulin (insa) promoter (16). In adult

123 F1 animals, we identified a heritable 7 bp deletion (c.1086_1092del) in exon 4 that is predicted

124 to result in a frameshift and introduction of a premature stop codon at p.S364X (Fig 1A). We

125 identified multiple heterozygous F2 carriers of the deletion and in-crossed them to propagate a

126 homozygous alms $1^{-/}$line. We noted non-Mendelian ratios in progeny of heterozygous parents,

127 with homozygotes representing only $14 \%$ of genotyped adult fish ( $p=0.007$; Chi-Squared; Fig

128 1B), suggesting an important developmental role for alms1. alms $1^{-/-}$homozygous mutant

129 animals survived to adulthood and could be mated to produce viable progeny. Their offspring

130 also exhibited high rates of curly tail phenotype at 3 days post-fertilization (dpf), which is typical

131 of zebrafish ciliary mutants (Fig 1C) (17). alms1 RNA and Alms1 protein levels were

132 dramatically decreased in alms $1^{-/}$animals (Fig 1D-E). Intermediate RNA levels were identified

133 in heterozygote animals, although no morphological abnormalities were observed (Fig S1A).

134 Interestingly, visible morphological defects including the body curvature phenotype were rarely

135 observed in homozygous progeny of alms $1^{+-}$parents, potentially suggesting a maternal

136 contribution of alms1 to early development.

138 Zebrafish alms1 ${ }^{-/}$phenocopies features of Alström syndrome including cardiomyopathy, 139 retinal dystrophy and renal defects

$140 \quad$ Having identified viable homozygous alms 1 mutants, we examined broader phenotypes in

$141 \mathrm{alms} 1^{-/}$progeny. Alström syndrome patients and mouse mutant models exhibit a wide range of

142 phenotypes across multiple organ systems $(4,18)$. We examined mutants to assess the

143 presence of prominent features associated with the disorder in both embryonic and adult

144 tissues. 
145 Nearly two-thirds of Alström syndrome patients present with dilated cardiomyopathy and 146 congestive heart failure contributes to a significant portion of the reported mortality (19). The

147 earliest manifestation of cardiomyopathy in zebrafish is cardiac edema, which results from failed 148 contractility, loss of vascular integrity or ventricular malformations and can develop by $48 \mathrm{hpf}$ 149 (20). Compared to $2.5 \%$ of wild type control animals generated from sibling clutch-mates, $18 \%$ 150 of alms $1^{-/}$embryos exhibited cardiac edema at $48 \mathrm{hpf}$ (Fig 2A-B). Although this reflected a 6-

151 fold increase in edema ( $p<0.0001$; Observed vs Expected), the majority of alms $1^{\%}$ embryos

152 appeared largely normal (Fig 2A-B). To examine the possibility of a progressive cardiac

153 phenotype, we also examined the morphology of age-matched adult hearts in alms $1^{-/}$animals.

154 We observed smaller hearts in the adult alms $1^{-1-}$ fish when compared with wildtype controls (Fig $\left.1552 \mathrm{C}^{\prime}\right)$. Closer examination revealed a loss of ventricular wall integrity in the alms $1^{-/}$fish (Fig $2 \mathrm{C}$ ").

156 These findings are consistent with cardiomyopathy in Alström, including the reported variability

157 in phenotypic presentation in patients (19).

158 Degeneration of the retina is also typical in Alström patients with individuals presenting with

159 visual impairment within a few weeks of birth and typically becoming completely blind before

160 age 30 as a result of progressive loss of photoreceptors $(4,21)$. We assessed retinas of alms $1^{+/+}$

161 adults and found no impairment of the retinal architecture, with the ganglion cell layer, the 162 plexiform layers, and photoreceptor layers all intact (Fig 2D). The alms $1^{-/}$adults exhibited 163 reduced retinal integrity, most notably in both the inner and outer photoreceptor layers which 164 were visibly reduced (Fig 2D). These observations are consistent with the retinal degeneration 165 and subsequent blindness found in human patients. To assess functional impact of alms ${ }^{-/}$on 166 vision, we performed full-field electroretinograms (ERGs) on alms $1^{+/+}$and alms ${ }^{-/-}$zebrafish at 9 167 months of age. Non-invasive in vivo scotopic ERGs showed attenuated b-wave amplitudes in 168 the alms ${ }^{-/}$zebrafish as compared to controls (Fig 2E), indicating reduced photoreceptor 169 response in these animals. Intriguingly, we noticed age-dependent reduced motility and 170 decreased food seeking behavior in alms 1 \% mutants, consistent with severe vision loss (data not 
171 shown). Together with the histological findings, these data implicate Alms1 in maintenance of

172 retinal sensory epithelia and visual function.

173 Nearly half of Alström patients have reported renal failure accompanied by a broad range of

174 defects including calculi, interstitial fibrosis, and glomerulosclerosis (4). We examined gross

175 kidney morphology in H\&E-stained sections of kidneys from alms $1^{+/+}$adults, and observed well-

176 formed tubule structure of varying intensities, indicating distal (lighter stain, yellow arrow) and

177 proximal (darker stain, red arrow) tubules (Fig 2F). The alms $1^{-/-}$kidney sections contained

178 apparent interstitial degradation and distal and proximal tubules were dilated compared to

179 control animals (Fig 2F, colored arrows). These observations are consistent with degradation of

180 the tubules and interstitial space and with previously reported phenotypes in $A / m s 1^{--}$mice (18).

\section{2 alms $1^{-/-}$zebrafish exhibit systemic metabolic defects}

183 Having confirmed the presence of previously reported prominent multi-organ features in the

$184 \mathrm{alms} 1^{-/}$zebrafish $(4,18,19)$, we explored the possibility of metabolic defects. Alström patients

185 exhibit high rates of early onset obesity coupled with hyperinsulinemia and progression to frank

186 T2DM, often as early as the second decade of life (4). To examine the possibility of increased

187 weight gain, we subjected adult wild type or mutant fish clutch-mates to an 8-week dietary

188 regimen consisting of either regular pellet diet (control diet) or a ten-fold increased weight of

189 pellet diet supplemented with five-fold weight of egg yolk powder (high fat diet) $(22,23)$. alms $1^{+/+}$

190 fish did not gain significant weight on the control diet, but the high fat diet produced an increase

191 of 1.9 -fold over the starting weight at 8 weeks in these animals ( $p=0.033$; Two-Way ANOVA; Fig

$1923 \mathrm{~A}-\mathrm{B})$. By comparison, the alms $1^{-/-}$fish gained weight under all dietary conditions. Control diet in

$193 \mathrm{alms} 1^{-/-}$fish resulted in a 1.6-fold increase over starting weight and the high fat diet produced a

194 3.2-fold increase in weight over the 8-week time period. Notably, significant weight gain was

195 apparent after only 3 weeks of high fat feeding ( $p=0.021$; Two-Way ANOVA; Fig 3A-B). We did 
196 not observe quantifiable differences in food intake at larval stages, as such we propose that the

197 obesity phenotype is unrelated to central regulation of satiety or hunger (Fig S1B).

198 The truncal obesity typically observed in Alström patients is often accompanied by hepatic

199 steatosis, a common hepatic manifestation of metabolic syndrome. Fatty liver has been reported

200 in a substantial proportion of patients as well as mouse Alström models $(4,18)$. To determine if

201 mutant zebrafish exhibit abnormal accumulation of hepatic lipids, we stained wholemount $6 \mathrm{dpf}$

202 larvae with Oil Red O and examined neutral lipid content in the liver (Fig 3C). Only 18\% of

$203 \mathrm{alms}^{+/+}$embryos exhibited observable and dense Oil Red O staining in their livers, while $82 \%$

204 of alms $1^{-1-}$ embryos exhibited excess fat deposition ( $p<0.0001$; Observed vs Expected; Fig 3C).

205 By adult stages this was accompanied by hypertrophy of hepatopancreata of alms $1^{-/}$fish,

206 demonstrated by increased cell density when compared to age- and section-matched wild type

207 animals (Fig 3D).

208 Excessive weight gain and hepatic steatosis are indicative of metabolic dysfunction and 209 could suggest insulin resistance and impaired glucose disposal. To evaluate glucose uptake in

210 alms 1 mutant fish, we exposed 6 dpf larvae to 2-(N-(7-Nitrobenz-2oxa-1,3-diazol-4-yl)Amino)-2-

211 Deoxyglucose (2-NBDG), a fluorescently labeled glucose analog, and quantified fluorescence

212 intensity in larval kidneys after 4 hours (24). alms $1^{+/+}$animals exhibited a dose-dependent

213 increase in fluorescence upon exposure to increasing concentrations, reaching a 9.75-fold \pm

2143.53 increase over baseline with $1000 \mu \mathrm{M}$ 2-NBDG ( $p=0.0003$; Two-Way ANOVA; Fig 3E).

$215 \mathrm{alms} 1^{-/-}$larvae, however, did not exhibit any marked increase in fluorescence, reaching only 1.8-

216 fold \pm 2.44 over baseline with $1000 \mu \mathrm{M}$ 2-NBDG ( $p=0.37$; Two-Way ANOVA; Fig 3E), consistent

217 with impaired glucose disposal and, potentially, insulin resistance. To further probe this latter

218 possibility, we quantified insulin levels by high-sensitivity insulin ELISA in pooled protein lysates

219 from $5 \mathrm{dpf}$ larvae and found a 2.36-fold increase in insulin levels in alms $1^{-/}$larvae $(\mathrm{p}<0.0001$;

220 Student's t-test; Fig 3F), consistent with hyperinsulinemia. 


\section{2 alms $1^{-/}$zebrafish display impaired $\beta$-cell function}

223 While hyperinsulinemia and insulin resistance provide the physiological foundation for

224 diabetes, loss of $\beta$-cell mass and function is the hallmark of progression to disease. We

225 previously described increased $\beta$-cell apoptosis and decreased $\beta$-cell proliferation in alms 1

226 knockdown in zebrafish larvae (15), indicating a $\beta$-cell deficiency in Alström-associated

227 diabetes. Consistent with these data, alms $1^{-/}$adult pancreatic tissue lacked integrity and had

228 fewer insulin granule-positive areas when compared to location-matched control tissues (Fig

$2294 \mathrm{~A})$. At $5 \mathrm{dpf}$ larval stages, alms $1^{-/-}$larvae contained an average of $20.4 \pm 1.3 \beta$-cells per fish,

230 which is a reduction from the $31.9 \pm 1.0 \beta$-cells per fish in controls $(p<0.0001$; Student's t-test;

231 Fig 4B). Given the reduced $\beta$-cell mass in alms $1^{-/}$animals at all stages, we hypothesized an

232 inability to appropriately sense and regulate systemic glucose in alms $1^{-/}$animals. Proper

233 sensing of high glucose conditions results in expansion of $\beta$-cell mass (25). We evaluated this

234 response using alms $1^{+/-}$progeny treated with either glucose-free standard embryo media or

235 media supplemented with high glucose (40 mM) from 24-120 hpf. Larvae were fixed and

236 mCherry+ $\beta$-cells were imaged and counted prior to genotyping (Fig 4C). This blinded analysis

237 demonstrated $\beta$-cell expansion in wildtype siblings grown in $40 \mathrm{mM}$ glucose media from an

238 average of $30.6 \pm 1.1$ to $36.7 \pm 1.9 \beta$-cells per fish ( $p=0.0049$; One-Way ANOVA; Fig 4D),

239 consistent with our previous observations (15). The alms $1^{-/-}$larvae again exhibited reduced

240 numbers of $\beta$-cells under control conditions, an average of $27.0 \pm 1.1 \beta$-cells, and failed to

241 increase the number of $\beta$-cells after high glucose exposure, an average of $29.1 \pm 0.9 \beta$-cells per

242 fish ( $p=0.0671$; One-Way ANOVA; Fig 4E), implicating Alms1 in the $\beta$-cell response to elevated

243 systemic glucose.

$244 \quad$ The $\beta$-cell deficits and elevated systemic insulin suggest a pathophysiology in which $\beta$-cells

245 are hypersecretory and also unable to properly regulate insulin secretion in response to 
246 exogenous cues. To better understand how loss of alms 1 may impact $\beta$-cell function, we

247 generated single-cell homogenates from $5 \mathrm{dpf}$ larvae of either wildtype $\mathrm{Tg}$ (insa:mCherry) or

$248 \mathrm{Tg}$ (insa:mCherry);alms $1^{-/-}$and isolated the mCherry+ cells via FACS sorting (Fig 5A) (26). Using

249 RNA from the isolated cells, we carried out whole transcriptome analysis via RNA-Seq $(26,27)$.

250 Using a cut-off for differentially expressed genes of a fold change of greater than 1 or less than -

251 1, we identified a total of 3,880 up-regulated genes and 5,531 down-regulated genes in the

$252 \mathrm{alms} 1^{-/} \beta$-cells compared to $\beta$-cells isolated from wild type larvae (Fig 5B). We first confirmed

253 the $\beta$-cell-enriched nature of these cells by confirming elevation of islet and $\beta$-cell markers,

254 relative to markers of other cell types (Fig 5C). We then carried out pathway analysis of

255 significantly changed genes and found that the down-regulated genes in mutant $\beta$-cells strongly

256 supported a generalized decrease in cellular activities, protein and RNA processing, consistent

257 with the significant apoptosis that we previously reported (Fig S2) (15). Over-represented terms

258 in the set of upregulated genes were in large part related to cellular transport and secretion (37

259 of 74 categories) and cell membrane ion transport (Fig S3A). These findings support a role for

260 alms 1 in regulation of secretion and membrane depolarization in $\beta$-cells. We also identified a

261 group of significantly abundant pathways in the up-regulated genes with known pancreatic

262 functions (Fig S3B). These genes can be clustered into those implicated in monogenic diabetes,

263 nutrient transport (mainly metal ion and amino acids carriers), insulin secretion (including

264 calcium and potassium channels), and generalized pancreatic secretion (Fig 5C). The

265 intersections of these pancreas-related pathways contain a subset of six genes, including

266 slc2a2/glut2, found in 3 pathways, and insulin, found in 2 pathways (red numbers, Fig 5C).

268 Depletion of $\boldsymbol{A l m s} 1$ in cultured $\beta$-cells impairs glucose challenge response

269 Given the identified functional defects in alms $1^{-/} \beta$-cells and the implication of insulin

270 secretion defects from transcriptomic data, we hypothesized that the diabetes phenotype may 
271 be linked to dysregulated insulin secretion in the absence of Alms1. Thus, we evaluated the

272 mechanism by which ALMS1 impacts insulin secretion using a simplified cultured mouse $\beta$-cell

273 model, MIN6.

$274 \quad$ Alms1 knockdown was accomplished via transient siRNA transfection (si-Alms1) with an

275 average of $0.38 \pm 0.04$ Alms 1 expression compared to control levels $(p<0.0001$; Student's t-test;

276 Fig S1C). We next examined the genes implicated by RNA-Seq in cultured $\beta$-cells. When

277 exposed to $16.7 \mathrm{mM}$ glucose, physiological high glucose conditions, control cultured $\beta$-cells

278 showed an increase in adenylyl cyclase 5 (Adcy5) and calcium/calmodulin-dependent protein

279 kinase 2b (Camk2b), both known to transmit signals downstream of glucose transport in murine

$280 \quad \beta$-cells, along with moderate changes to $P k l r$, which initiates intracellular glucose processing

281 and alters cellular metabolism, and S/c2a2, the main murine glucose transporter (Fig 5E) (28).

282 Of note, the si-Alms $1 \beta$-cells exhibited a dampened Adcy5 response and higher levels of

283 Camk2b gene expression profiles ( $p=0.002$; Two-Way ANOVA) irrespective of glucose levels

284 (Fig 5E). This appeared to be accompanied by a failure to alter Pklr and Slc2a2 expression in

285 response to glucose (Fig 5E). In fact, Pklr appeared to mimic high glucose control conditions

286 even in si-Alms1 $\beta$-cells cultured in low glucose conditions (Fig 5E), suggesting an inability to

287 properly sense glucose and regulate gene expression.

288 These gene expression data led us to hypothesize that the si-Alms $1 \beta$-cells would potentially

289 exhibit inappropriate insulin secretion in response to high glucose. The secreted insulin upon

290 stimulation with physiological high glucose in si-Alms $1 \beta$-cells was evaluated using high-

291 sensitivity ELISA based quantification. The control $\beta$-cells required 10 minutes to begin

292 secreting insulin in response to high glucose, and reached 2.2-fold the unstimulated insulin

293 levels by 30 minutes (Fig 5F). The si-Alms $1 \beta$-cells showed 1.6-fold higher levels of secreted

294 insulin than control $\beta$-cells without glucose stimulation (Fig 5F). After 30 minutes of high

295 glucose, the si-Alms $1 \beta$-cells were at only 0.88 -fold of unstimulated control levels $(p=0.032$; 
296 Two-Way ANOVA; Fig 5F). These data suggest a modest hypersecretory basal state in

297 unstimulated Alström $\beta$-cells accompanied by an impairment in glucose-stimulated insulin

298 secretion.

300 DISCUSSION

These studies characterized the physiologic and phenotypic responses of a newly generated Alström model created in zebrafish using CRISPR/Cas9. This new mutant line not only exhibits reduced Alms1 RNA and protein levels with body dysmorphogenesis of known

304 zebrafish ciliary genes (Fig 1) $(17,29)$, but demonstrates the known physiological defects of both

305 Alström patients and the mouse Alström model, including functional retinal degradation and renal tubule dilation (Fig 2) (4,18). Given the molecular changes and phenotypic differences, we

307 concluded this Cas9-induced deletion represents a loss-of-function mutant model of the obesity 308 ciliopathy, Alström syndrome.

309 Since a defining characteristic of this ciliopathy is obesity, we examined and demonstrated a 310 propensity for excess weight gain and inappropriate lipid storage, implicating Alms1 in zebrafish 311 metabolic regulation (Fig 3). These conserved effects are of particular interest as the metabolic 312 organs of the zebrafish closely mimic those of human physiology $(13,14)$. In particular, adipose 313 depot locations, and governing hormones are all conserved between zebrafish and humans

$314(30,31)$. Furthermore, as is often found in the general obese population, Alström patients exhibit 315 hyperinsulinemia, insulin resistance and type 2 diabetes mellitus (32). The alms1 mutant 316 zebrafish displayed characteristics supporting a conserved role for the gene. Namely, the alms $1^{-}$

317 fish are hyperinsulinemic, fail to respond to glucose challenges and have islets with reduced $\beta$ 318 cell numbers (Fig 3-4). Beyond the reduced overall $\beta$-cell mass, the remaining $\beta$-cells in alms $1^{-/}$ 319 animals are unhealthy and improperly functioning. RNA-Seq gene expression analysis in cells 320 isolated from alms $1^{--}$animals show excess secretory activity, especially in insulin-related genes, 
321 and cellular transport alongside an overall decrease in transcription and translation (Fig 5, Fig

322 S2-S3). Consistent with this conclusion was the hyperinsulinemia in larval zebrafish and insulin

323 hypersecretion in unstimulated cultured $\beta$-cells. Glucose-stimulated insulin secretion was,

324 however, severely impaired in cultured $\beta$-cells as was the response of larval $\beta$-cells to high

325 glucose conditions. These defects combined with the significant changes in expression of genes

326 involved in secretory pathways lead us to conclude that unstimulated $\beta$-cells without alms 1 are

327 hypersecretory.

328 Based on these observations, we propose unstimulated basal $\beta$-cell hypersecretion as a

329 primary driver of hyperinsulinemia in alms $1^{-1-}$ animals. Insight from RNA-Seq gene expression

330 changes and observed phenotypic responses lead us to propose two aspects of $\beta$-cell function

331 that are reliant upon Alms1: 1) control of insulin secretion in the absence of stimuli and 2)

332 appropriate $\beta$-cell glucose sensing. We used a simplified $\beta$-cell culture system to examine these

333 aspects individually. Knockdown of Alms1 resulted in excess secreted insulin without glucose

334 stimulation, but failure to respond to high glucose stimulation at the level of either insulin

335 secretion or altered gene expression (Fig 5). Epistatic analysis of the glucose-sensing and

336 insulin response pathways in Alms 1 knockdown or knockout $\beta$-cells will be important to identify

337 the exact genetic pathway defects in those cells and could be confirmed in the alms $1^{-/}$animals.

338 The molecular mechanism by which Alms1 impacts secretion is unknown, and such studies

339 would inform the function of the Alström protein in $\beta$-cells and potentially provide insight into its

340 role in other cell types. Importantly, our observations provide additional evidence of a central

341 role for $\beta$-cell cilia in sensing of extracellular stimuli that directly impact insulin secretion. Ciliary

342 localization of the insulin receptor in $\beta$-cells, for example, is critical to normal function (33).

343 Several adenylyl cyclases, including those encoded by $A D C Y 5$ and $A D C Y 8$, have also been

344 linked to cilia in other cell types $(34,35)$ and are critical for cAMP generation, a major regulator

345 of glucose-stimulated insulin secretion (36). It is therefore possible that disruption of Alms1 
346 impacts the ability to sense systemic insulin or glucose levels, resulting in a dysregulation of $\beta$ -

347 cell response to stimuli and subsequent secretion.

348 While the early onset insulin hypersecretion may contribute to systemic insulin resistance

349 and even lead to eventual $\beta$-cell exhaustion, this does not rule out the implication of peripheral

350 tissue insulin resistance that is also a major trigger of T2DM pathology. Given the non-tissue

351 specific nature of this mutant, the individual contributions of adipose or muscle tissue to the

352 observed diabetes phenotypes cannot be evaluated. The primary role of $\beta$-cell dysfunction in

353 T2DM versus a secondary defect to peripheral insulin resistance is currently a topic of debate

354 (37,38). Generation of tissue-specific deletion of alms1, including peripheral tissues and $\beta$-cell-

355 specific knockout, will permit analysis of the cell-autonomous role for Alms 1 in the context of

356 systemic dysfunction. The utility of the zebrafish and its recapitulation of human disease

357 phenotypes with high fidelity suggest that these genetic models of diabetes can be useful tools

358 in isolating the root cause of $\beta$-cell failure and T2DM etiology.

360 MATERIALS AND METHODS

361 Zebrafish Husbandry and Stocks

362 Experiments were performed using the $\mathrm{Tg}$ (insa:mCherry) from the Zebrafish International

363 Resource Center. Adult fish were screened and a 7 bp deletion in exon 4 of alms 1 was

364 identified, resulting in the $\mathrm{Tg}$ (insa:mCherry);alms $1^{-/}$line. Embryos were raised at $28.5^{\circ} \mathrm{C}$ for all

365 experimental analyses. Adult zebrafish were housed and mated naturally, based upon standard

366 protocols (ZIRC). All zebrafish work was conducted in accordance with the University of

367 Maryland Baltimore IUCAC guidelines. 
370 For histological analyses, adult fish—approximately six months in age—were sacrificed in

$3710.05 \%$ tricaine (3-amino benzoic acid ethyl ester) until unresponsive (Sigma). The tail segment

372 behind the anal fin was removed using a razor blade and samples were fixed for $24 \mathrm{hrs}$ in

373 Dietrich's solution (30\% ethanol, $10 \%$ formalin, $2 \%$ glacial acetic acid) then decalcified in $0.5 \mathrm{M}$

374 ethylenediaminetetraacetic acid for 7 days. Samples were processed for cryo-sectioning using

375 serial sucrose gradient before being embedded in optimal cutting temperature (OCT) compound

376 (Tissue-Tek). Samples were sectioned into $10 \mu \mathrm{M}$ thick transverse sections and mounted.

377 Hemotoxylin (Thermo Scientific) and Eosin Y (95\%, Sigma) staining was performed to evaluate

378 overall tissue morphology. Aldehyde fuchsin staining (18) with Fast Green counterstain (Sigma)

379 was performed to examine insulin+ tissues. Images were collected on a Nikon Eclipse at 10-

$38040 X$

381 Visual responses were examined in adult fish-approximately nine months old-that were

382 dark adapted overnight. All following procedures were done under dim red light. Fish were

383 anesthetized by submersion in tricaine solution. After anesthesia, zebrafish were transferred to

384 wet Whatman filter paper stack and immobilized by injection of $10 \mu \mathrm{L}$ of $25 \mathrm{mg} / \mathrm{ml}$ gallamine

385 triethiodide (Enzo Life Sciences) below the gill. Anesthesia was maintained with continuous

386 perfusion of tricaine-containing oxygenated system water. The reference $\mathrm{AgCl}$ electrode was

387 placed near the eye and the recording electrode was placed on the eye. The fish with attached

388 electrodes was placed in a Ganzfeld chamber and presented with increasing scotopic stimuli

$389(0.025-9.952 \mathrm{~cd} \times \mathrm{s} / \mathrm{m} 2)$ at 10-60 sec intervals using UTAS BigShot (LKC Technologies). A

390 minimum 3 waveforms per intensity were averaged.

$391 \quad$ Adult feed studies were carried out in $1 \mathrm{~L}$ tanks containing genotyped clutch-mates starting

392 at 3 months of age. The volumes of food were modified from published protocols $(22,23)$.

393 Control diet volume was assessed prior to beginning the experiment as the amount of food

394 consumed by wild type fish in 5 minutes. Fish were fed once a day with assigned dietary

395 conditions and the length and weight were quantified at indicated time points. The food volume 
396 was calculated after each weight measurement to account for weight gain throughout the study

397 period.

$398 \quad$ All image processing and analyses were carried out using Fiji (39).

400 Embryonic Zebrafish Analyses and Imaging

$401 \quad$ Fat content in larval livers were examined after yolk absorption was complete, 5-7 dpf, via

402 Oil Red O staining of whole animals fixed in 4\% paraformaldehyde (PFA). Fatty liver was

403 identified by Oil Red O accumulation in the liver area, found on the right side of yolk-depleted

404 larvae. All images were collected on a Zeiss Axioscope.

$405 \quad \beta$-cell analyses were performed at the indicated time points using previously published

406 protocols $(15,25,40)$. Briefly, the mCherry+ cells were counted $\beta$-cells in larvae containing the

407 Tg(insa:mCherry) transgene after fixation in 4\% PFA and post-fixation in methanol. Larvae were

408 placed with the left lateral side facing the slide and compressed under coverslips with Prolong

409 Gold antifade (Life Technologies) media. Tg(insa:mCherry);alms $1^{+/-}$progeny were glucose

410 challenged using medium supplemented with $40 \mathrm{mM}$ glucose at $24 \mathrm{hpf}$ and collected at $5 \mathrm{dpf}$ for

$411 \beta$-cell analysis. Control conditions were standard embryo medium. After $\beta$-cell counts were

412 collected the alms1 genomic identity of each larva was determined via PCR genotyping. Images

413 were collected on a Nixon W1 using a 40x objective.

414 Embryonic feeding assays were performed as previously published (41). Briefly, equal

415 amounts of BODIPY FL C12 (Life Technologies) egg yolk were provided to 7 days post

416 fertilization (dpf) larvae for a period of 4 hours at $28.5^{\circ} \mathrm{C}$. The embryos were then lysed and

417 total fluorescence at $510 \mathrm{~nm}$ was quantified.

$418 \quad$ Glucose uptake and insulin levels were evaluated in 5 dpf larvae. 2-(N-(7-Nitrobenz-2oxa-

419 1,3-diazol-4-yl)Amino)-2-Deoxyglucose (2-NBDG) in dimethyl sulfoxide (DMSO) was provided to 420 larvae at $300-1,000 \mu \mathrm{M}$ in embryo medium at $28.5^{\circ} \mathrm{C}$ for $4 \mathrm{hrs}$. The larvae were then rinsed $4 \mathrm{X}$ 
421 with embryo medium and anesthetized before imaging. All images were collected on a Zeiss

422 Axioscope. Glucose uptake was evaluated as total fluorescence in the embryonic kidney by

423 ImageJ, relative to DMSO alone. Larval insulin levels were evaluated in pooled larval lysates,

424 mechanically dissociated in Nonidet P-40 protein buffer, using high-sensitivity insulin ELISA 425 (Mercordia).

426 All image processing and analyses were carried out using Fiji (39).

RNA-sequencing of Isolated Preparation $\beta$-cells

$5 \mathrm{dpf}$ larvae from $\mathrm{Tg}$ (insa:mCherry) and $\mathrm{Tg}$ (insa:mCherry);alms $1^{-/-}$were dissociated into

430 single cells and sorted via mCherry+ signal using a BD FACS Aria II (BD BioSciences) (26).

431 RNA was extracted from isolated cell fraction using an RNA extraction kit (Qiagen). RNA

432 quantity and quality were assessed via 260/280 absorption. Samples were provided in duplicate

433 for library preparation and quantitative analysis using Next Generation Sequencing and an

434 Illumina HiSeq 2x150 PE (GENEWIZ). Fragments were aligned to the GRZ10 genome with CLC

435 Genomics Server program v10.0.1. Full expression datasets are deposited at GEO and

436 available upon request.

438 Analyses of RNA-Seq Expression datasets

439 Analysis of the identified list of significantly differentially expressed genes was performed as

440 previously published (26). Pathway interactions were visualized using ConsensusPath DB

$441(42,43)$ and ontology clusters were evaluated using the Gene Ontology Consortium $(44,45)$.

\section{Cell Culture}

$444 \quad$ Culture of MIN6 cells (CRL11506; American Type Culture Collection) were cultured in

445 DMEM-H (American Type Culture Collection) supplemented with 15\% heat-inactivated fetal

446 bovine serum (FBS) and 1X penicillin/streptomycin (Sigma). Knockdowns were accomplished 
447 using Lipofectamine 3000 (Life Technologies) and either scrambled control or Alms 1-targeted

448 siRNA (Life Technologies). Efficacy of siRNA knockdown was evaluated via qRT-PCR.

449 Glucose stimulation of cultured $\beta$-cells was performed on cells plated at equal densities, as

450 determined by hemocytometer counts, using $2.5 \mathrm{mM}$ and $16.7 \mathrm{mM}$ glucose as baseline and

451 high glucose concentrations, respectively. Insulin was assessed in media collected at the

452 indicated time points using high-sensitivity insulin ELISA (Mercordia).

\section{Western blots}

$4555 \mathrm{dpf}$ zebrafish were mechanically homogenized using mortar and pestle in NP-40 buffer 456 supplemented with protease and phosphatase inhibitor (Sigma). Homogenized tissue was

457 incubated on ice for 15 mins with regular vortexing to lyse. Lysates were centrifuged at 9,400 $\mathrm{g}$

458 for 10 minutes and the supernatant was collected. Lysate supernatant was boiled with Laemmli 459 sample buffer at $95^{\circ} \mathrm{C}$ for 10 mins. Equal amounts of protein were loaded and transferred onto 460 a nitrocellulose membrane. Membranes were blocked for $1 \mathrm{hr}$ in Tris-buffered saline (TBS) with $4610.1 \%$ Tween-20 and 5\% BSA. Membranes were then incubated overnight with Goat Anti-Alms1

462 (1:500; Abcam) or Rabbit Anti-Actin (1:2,000; Sigma). Detection of specific proteins was

463 accomplished after $1 \mathrm{hr}$ incubation with species specific HRP-conjugated secondary antibody

464 (1:15,000; Jackson Immuno) and application of ECL Substrate (Pierce). Protein intensity was

465 normalized to actin and quantified via densitometry function in ImageJ.

467 qRT-PCR

468 RNA was extracted using RiboZOL RNA Extraction Reagent (VWR) and converted to cDNA 469 via the FirstStrand cDNA Synthesis kit (Thermo Scientific), according to manufacturer protocols. 470 Target gene expression was determined on a LightCycler 480 (Roche) using 2X SYBR Green 
471 Master Mix (Roche) and compared by $\Delta \Delta \mathrm{CT}$. Actin and GADPH were used as control in

472 zebrafish and cultured cells, respectively. Primer sequences are available upon request.

473

\section{Statistical Analysis}

475 All experiments represent a minimum of three replicates, with the number of analyzed samples

476 (n) provided. Prism 6.0 software (GraphPad) was used to determine appropriate analyses and

477 statistical significance and is provided in individual figures.

479 Ethics Statement

480 All animal research was approved by the University of Maryland Baltimore Institutional Animal

481 Care and Use Committee (IACUC), approval \#0116027.

\section{AUTHOR CONTRIBUTIONS}

484 JEN designed and performed experiments, analyzed data, and wrote the manuscript. TLH 485 generated the mutant line and performed the dietary experiments. CCL perform Oil Red O 486 experiments. RM performed embryonic dietary assays. SL assisted in mutant line generation.

487 MSM and $\mathrm{RH}$ performed cryopreservation and tissue sectioning. SS and ZMA performed 488 photoreceptor function tests. CJW contributed the FACS sorting experiment. NAZ contributed 489 experimental design and wrote the manuscript.

\section{$491 \quad$ ACKNOWLEDGEMENTS}

492 The authors wish to thank the University of Maryland School of Medicine Center for Innovative

493 Biomedical Resources, Confocal Microscopy Core in Baltimore, MD for equipment use and

494 assistance with image acquisition. Jonathan Van Ryzin and Margaret McCarthy's laboratory at the 495 University of Maryland, Baltimore were invaluable in the acquisition of the histology images. The 
496 zebrafish $\beta$-cell isolation was carried out with assistance from and use of the CCR Frederick

497 Flow Cytometry Core.

498 This work was funded by the grants from the National Institutes of Health in Bethesda, MD.

499 Specific funding was provided by grants from the National Institutes of Diabetes, Digestive and

500 Kidney Disorders-R01DK102001 (NAZ), P30DK072488 (NAZ and RM), T32DK098107 (JN

501 and TLH), and F31DK115179 (TLH)—and the National Institute on Deafness and other

502 Communication Disorders-R01DC013817 (RH), R01DC016295 (ZMA), and F31DC016218

503 (MSM).

504

505 COMPETING INTERESTS

$506 \quad$ The authors do not declare any conflicting interests.

507

508 REFERENCES CITED

509 1. Goetz SC, Anderson K V. The primary cilium: a signalling centre during vertebrate

510 development. Nat Genet. 2010;11:331-44.

511 2. Adams M, Smith UM, Logan C V., Johnson CA. Recent advances in the molecular 512 pathology, cell biology and genetics of ciliopathies. J Med Genet. 2008;45(5):257-67.

513 3. Lodh S, O'Hare EA, Zaghloul NA. Primary cilia in pancreatic development and disease.

$514 \quad$ Birth Defects Res Part C - Embryo Today Rev. 2014;

515 4. Marshall JD, Maffei P, Collin GB, Naggert JK. Alström Syndrome: Genetics and Clinical $516 \quad$ Overview. Curr Genomics. 2011;12:225-35.

517 5. Alstrom $\mathrm{CH}$, Hallgren B, Nilsson LB, Asander H. Retinal degeneration combined with 518 obesity, diabetes mellitus and neurogenous deafness: a specific syndrome (not hitherto 519 described) distinct from the Laurence-Moon-Bardet-Biedl syndrome. Acta Psychiatr $520 \quad$ Neurol Scand Suppl [Internet]. 1959;129:1-35. Available from:

$521 \quad$ http://www.ncbi.nlm.nih.gov/pubmed/13649370 
522 6. Hearn T, Spalluto C, Phillips VJ, Renforth GL, Copin N, Hanley NA, et al. in the Pathogenesis of Obesity , Insulin Resistance , and Type 2 Diabetes. 2005;54(May):15817.

525 7. Collin GB, Marshall JD, King BL, Milan G, Maffei P, Jagger DJ, et al. The alström syndrome protein, ALMS1, interacts with a-actinin and components of the endosome recycling pathway. PLoS One. 2012;7(5).

8. Leitch CC, Lodh S, Prieto-Echague V, Badano JL, Zaghloul NA. Basal body proteins regulate Notch signaling through endosomal trafficking. J Cell Sci [Internet]. 2014;127(11):2407-19. Available from: http://jcs.biologists.org/cgi/doi/10.1242/jcs.130344

9. Mathavan S, Lee SGP, Mak A, Miller LD, Murthy KRK, Govindarajan KR, et al. Transcriptome Analysis of Zebrafish Embryogenesis Using Microarrays. PLoS Genet [Internet]. 2005;1(2):e29. Available from: http://dx.plos.org/10.1371/journal.pgen.0010029

10. Irion U, Krauss J, Nusslein-Volhard C. Precise and efficient genome editing in zebrafish using the CRISPR/Cas9 system. Development [Internet]. 2014;141(24):4827-30. Available from: http://dev.biologists.org/cgi/doi/10.1242/dev.115584

11. Vesterlund L, Jiao H, Unneberg P, Hovatta O, Kere J. The zebrafish transcriptome during early development. BMC Dev Biol. 2011;11.

12. Howe K, Clark MD, Torroja CF, Torrance J, Berthelot C, Muffato M, et al. The zebrafish

543 13. Santoro MM. Zebrafish as a model to explore cell metabolism. Trends Endocrinol Metab 544 [Internet]. 2014;25(10):546-54. Available from:

$545 \quad$ http://dx.doi.org/10.1016/j.tem.2014.06.003

546 14. Seth A, Stemple DL, Barroso I. The emerging use of zebrafish to model metabolic 547 disease. Dis Model Mech [Internet]. 2013;6(5):1080-8. Available from: 
15. Lodh S, Hostelley TL, Leitch CC, O'Hare EA, Zaghloul NA. Differential effects on $\beta$-cell mass by disruption of Bardet-Biedl syndrome or Alstrom syndrome genes. Hum Mol Genet. 2016;

16. Pisharath $\mathrm{H}$, Rhee JM, Swanson MA, Leach SD, Parsons MJ. Targeted ablation of beta cells in the embryonic zebrafish pancreas using E. coli nitroreductase. Mech Dev. 2007;124(3):218-29.

17. Zhao C, Malicki J. Genetic defects of pronephric cilia in zebrafish. Mech Dev [Internet]. 2007 Aug;124(7-8):605-16. Available from: http://www.ncbi.nlm.nih.gov/pubmed/17576052

558 18. Collin GB, Cyr E, Bronson R, Marshall JD, Gifford EJ, Hicks W, et al. Alms1-disrupted mice recapitulate human Alström syndrome. Hum Mol Genet. 2005;

19. Brofferio A, Sachdev V, Hannoush H, Marshall JD, Naggert JK, Sidenko S, et al. on 38 patients. Mol Genet Metab. 2017;121(4):336-43.

563 20. Stainier DY, Fouquet B, Chen JN, Warren KS, Weinstein BM, Meiler SE, et al. Mutations affecting the formation and function of the cardiovascular system in the zebrafish embryo. Development. 1996;123:285-92.

21. Russell-Eggitt I, Harris CM, A K. Delayed visual maturation $\square$ : an update. Dev Med Child

571 23. Landgraf K, Schuster S, Meusel A, Garten A, Riemer T, Schleinitz D, et al. Short-term 572 overfeeding of zebrafish with normal or high-fat diet as a model for the development of 573 metabolically healthy versus unhealthy obesity. BMC Physiol. 2017;17(1):1-10. 
574 24. Lee J, Jung DW, Kim WH, Um JI, Yim SH, Oh WK, et al. Development of a highly visual, 575 simple, and rapid test for the discovery of novel insulin mimetics in living vertebrates. ACS Chem Biol. 2013;8(8):1803-14.

25. Li M, Maddison LA, Page-McCaw P, Chen W. Overnutrition induces -cell differentiation through prolonged activation of -cells in zebrafish larvae. AJP Endocrinol Metab [Internet]. 2014;306(7):E799-807. Available from: http://ajpendo.physiology.org/cgi/doi/10.1152/ajpendo.00686.2013

26. Nesmith JE, Hostelley TL, Zaghloul NA. Sample Preparation and Analysis of RNASeqbased Gene Expression Data from Zebrafish Video Link. J Vis Exp [Internet]. 2017;56187(12810). Available from: www.jove.com

27. Hostelley TL, Lodh S, Zaghloul NA. Whole organism transcriptome analysis of zebrafish models of Bardet-Biedl Syndrome and Alström Syndrome provides mechanistic insight into shared and divergent phenotypes. BMC Genomics. 2016;

28. Thorens B, Sarkar HK, Kaback HR, Lodish HF. Cloning and functional expression in bacteria of a novel glucose transporter present in liver, intestine, kidney, and betapancreatic islet cells. Cell [Internet]. 1988 Oct 21;55(2):281-90. Available from: http://www.ncbi.nlm.nih.gov/pubmed/3048704

29. Wilkinson CJ, Carl M, Harris WA. Cep70 and Cep131 contribute to ciliogenesis in

593 30. Minchin JEN, Rawls JF. A classification system for zebrafish adipose tissues. Dis Model Mech [Internet]. 2017;10(6):797-809. Available from:

596 31. Flynn EJ, Trent CM, Rawls JF. Ontogeny and nutritional control of adipogenesis in zebrafish ( Danio rerio ). J Lipid Res [Internet]. 2009;50(8):1641-52. Available from:

599 32. Favaretto F, Milan G, Collin GB, Marshall JD, Stasi F, Maffei P, et al. GLUT4 defects in 
adipose tissue are early signs of metabolic alterations in alms1GT/GT, a mouse model for obesity and insulin resistance. PLoS One. 2014;

602 33. Gerdes JM, Christou-Savina S, Xiong Y, Moede T, Moruzzi N, Karlsson-Edlund P, et al. Ciliary dysfunction impairs beta-cell insulin secretion and promotes development of type 2 diabetes in rodents. Nat Commun. 2014;

34. Vuolo L, Herrera A, Torroba B, Menendez A, Pons S. Ciliary adenylyl cyclases control the Hedgehog pathway. J Cell Sci. 2015;

35. Roger B, Papin J, Vacher P, Raoux M, Mulot A, Dubois M, et al. Adenylyl cyclase 8 is central to glucagon-like peptide 1 signalling and effects of chronically elevated glucose in rat and human pancreatic beta cells. Diabetologia. 2011;

36. Hodson DJ, Mitchell RK, Marselli L, Pullen TJ, Brias SG, Semplici F, et al. ADCY5

37. Goel P. Insulin resistance or hypersecretion? The ßIG picture revisited. J Theor Biol. 2015;

614 38. Corkey BE. Banting lecture 2011: Hyperinsulinemia: Cause or consequence? Diabetes. 2012;61(1):4-13.

39. Schindelin J, Arganda-Carreras I, Frise E, Kaynig V, Longair M, Pietzsch T, et al. Fiji: An open-source platform for biological-image analysis. Nat Methods. 2012;9(7):676-82.

618 40. O'Hare EA, Yerges-Armstrong LM, Perry JA, Shuldiner AR, Zaghloul NA. Assignment of Functional Relevance to Genes at Type 2 Diabetes-Associated Loci Through Investigation of $\beta$-Cell Mass Deficits. Mol Endocrinol [Internet]. 2016;30(4):429-45.

622 41. Otis JP, Farber SA. High-fat Feeding Paradigm for Larval Zebrafish: Feeding, Live 623 Imaging, and Quantification of Food Intake. J Vis Exp. 2016;116.

624 42. Kamburov A, Pentchev K, Galicka H, Wierling C, Lehrach H, Herwig R.

625 ConsensusPathDB: Toward a more complete picture of cell biology. Nucleic Acids Res. 
$626 \quad 2011 ; 39$ (SUPPL. 1):712-7.

627 43. Kamburov A, Wierling C, Lehrach H, Herwig R. ConsensusPathDB - A database for

628 integrating human functional interaction networks. Nucleic Acids Res. 2009;37(SUPPL.

629 1):623-8.

630 44. Ashburner M, Ball CA, Blake JA, Botstein D, Butler H, Cherry JM, et al. Gene ontology:

631 Tool for the unification of biology. Nat Genet. 2000;25(1):25-9.

632 45. Carbon S, Dietze H, Lewis SE, Mungall CJ, Munoz-Torres MC, Basu S, et al. Expansion

633 of the gene ontology knowledgebase and resources: The gene ontology consortium.

$634 \quad$ Nucleic Acids Res. 2017;45(D1):D331-8.

635 


\section{Fig 1. Generation of zebrafish alms $1^{-/ 2}$ line.}

637 (A) Schematic of alms1 genomic region with and without CRISPR/Cas9 induced deletion

638 resulting in premature stop codon (orange). Pull out indicates region in exon 4 with sgRNA

639 target (green) and deletion (red) generated using CRISPR/Cas9. (B) Ratios of identified mutants

640 in heterozygous in-cross progeny. Note the reduced rate of mutants relative to expected

641 mendelian ratios. (C) Representative images of alms $1^{+/+}(\mathrm{n}=82)$ and $\operatorname{alms} 1^{-/-}(\mathrm{n}=70)$ larvae at 5

642 days post-fertilization. Note the ciliopathy body dysmorphogenesis identified in alms $1^{-/}$larvae.

643 Scale bar, $1 \mathrm{~mm}$. (D) alms $1^{-/}$larvae demonstrate reduced cDNA expression levels compared to

$644 \mathrm{alms} 1^{+/+}$at 5 days post-fertilization (dpf). Statistics, Student's t-test, ${ }^{* * *} \mathrm{p}<0.0001 .(\mathrm{E})$ alms $1^{-1-}$

645 larvae demonstrate reduced protein levels compared to alms $1^{+/+}$at $5 \mathrm{dpf}$.

647 Fig 2. alms $1^{-/}$zebrafish display multiple defective organ systems.

648 (A) Representative images of alms $1^{+/+}$and alms $1^{-/}$larvae showing severe cardiac edema at 48

649 hours post-fertilization. Scale bar, $1 \mathrm{~mm}$. (B) Quantification of cardiac edema rates in alms $1^{+/+}$

$650(n=71)$ and alms $1^{-/}(n=44)$ larvae. Significance, Chi-squared, ${ }^{* * * *} p<0.0001$. (C) Adult cardiac

$651 \mathrm{H} \& \mathrm{E}$ sections from alms $1^{+/+}$and alms $1^{-/}$zebrafish at 6 months showing gross (scale bar, 500

$\left.652 \mu \mathrm{m} ; C^{\prime}\right)$ and high-magnification (scale bar, $25 \mu \mathrm{m}$; C") structures in the atrium and ventricle of

653 the heart. Note the diminished size and degraded ventricular wall composition in the alms $1^{-1-}$

654 animals. A: atrium, V: ventricle. (D) Representative images of H\&E staining of retinal layers.

655 Note degradation of multiple retinal layers in alms $1^{-/-}$animals. PR: photoreceptors, PL: plexiform

656 layers, GCL: ganglion cell layers. Scale bar, $50 \mu \mathrm{m}$. (E) Quantification of scotopic b-wave

657 amplitudes in response to light stimulation from alms $1^{+/+}(\mathrm{n}=4)$ and alms $^{-/}(\mathrm{n}=3)$ zebrafish at 9

658 months of age. (F) Representative H\&E images of kidneys in alms $1^{+/+}$and alms $1^{-/}$animals.

659 Note the abnormal shape and size of kidney tubules in alms $1^{-/}$animals. Distal tubule, yellow

660 arrow, proximal tubule, red arrow. Scale bar, $100 \mu \mathrm{m}$. Where indicated, ${ }^{*} \mathrm{p}<0.05,{ }^{* *}, \mathrm{p}<0.01$. 
662 Fig 3. alms $1^{-/}$zebrafish exhibit increased weight gain and systemic metabolic defects.

663 (A) alms $1^{+/+}$and alms $1^{-/}$zebrafish at 3 months were fed controlled diets of either

664 maintenance diet (control), or overfeeding with high fat (HF) diet for 8 weeks ( $\mathrm{n}=4-6$ animals per

665 condition). Statistics, Two-Way ANOVA compared to alms $1^{+/+}$control diet. (B) Representative

666 images of alms $1^{+/+}$and alms $1^{-/}$zebrafish after 8 weeks of either control diet or high fat diet. (C)

667 Representative images of Oil Red O staining in livers of alms $1^{+/+}(n=27)$ and alms $1^{-/}(n=23)$

668 larvae at $6 \mathrm{dpf}$. Scale bar, $500 \mu \mathrm{m}$. Quantification of Oil Red O positive livers. Significance, Chi-

669 squared. (D) Representative regions of sectioned H\&E liver tissue from alms $1^{+/+}$and alms $1^{-/}$

670 zebrafish at 6 months showing signs of hepatomegaly. Scale bar, $25 \mu \mathrm{m}$. BV: blood vessel. (E)

671 FITC-labeled glucose at indicated concentrations was provided to alms $1^{+/+}$larvae $(\mathrm{n}=5-8$ per

672 group) and alms $1^{-/}$larvae ( $n=5-12$ per group) for 4 hrs. The fluorescence intensity was

673 quantified for each genotype. Statistics, Two-Way ANOVA. (F) Relative insulin by ELISA-based

674 detection in alms $1^{+/}(n=100)$ and alms $1^{-/}(n=76)$ larvae at 5 days post-fertilization. Statistics,

675 Student's two-tailed t-test with Welch's Correction. Where indicated, * $p<0.05,{ }^{* *} p<0.01,{ }^{* * * *}$

$676 p<0.0001$.

677

678 Fig 4. alms1 $1^{-/}$zebrafish islets show reduced size and glucose responsiveness.

679 (A) Aldehyde fuchsin staining of sectioned zebrafish at 6 months showing aberrant islet

680 structure (dark purple regions) in alms $1^{-/}$as compared to alms $1^{+/+}$. Scale bar, $50 \mu \mathrm{m}$. (B) $\beta$-cell

681 imaging and quantification of $5 \mathrm{dpf}$ larvae in alms $1^{+/+}(\mathrm{n}=31)$ and alms $1^{-/}(\mathrm{n}=22)$ larvae. Scale

682 bar, $25 \mu \mathrm{m}$. Statistics, Student's t-test with Welch's Correction. (C) Representative images of $\beta$ -

683 cells with and without exposure to $40 \mathrm{mM}$ glucose in alms $1^{+/+}$and alms $1^{-/-}$larvae. Scale bar, 25

$684 \mu \mathrm{m}$. (D) Quantification of $\beta$-cells at $5 \mathrm{dpf}$ from alms $1^{+/+}(\mathrm{NT}=22, \mathrm{Glu}=31)$ and alms $1^{-/}(\mathrm{n}, \mathrm{NT}=25$, 
685 Glu=18) larvae. Statistics, One-Way ANOVA. Where indicated, ${ }^{*} p<0.05,{ }^{* *} p<0.01,{ }^{* *} p<0.001$, $686^{* * *} p<0.0001$.

\section{Fig 5. Alms1 influences glucose sensing in $\beta$-cells.}

689 (A) Schematic of experimental design for comparative gene expression in $\beta$-cell enriched

690 populations from age-matched control and alms $1^{-/}$larvae. (B) Volcano plot of significantly

691 differentially expressed genes from GRZ10 between control and alms $1^{-/}$larvae. (C) Selected

692 tissue specific genes identified in isolated alms $1^{+/+}$cells. Note the presence and high expression

693 of pancreatic markers. ND: not identified. (D) Subset of significantly up-regulated pathway

694 nodes, identified by ConsensusPath DB, in alms $1^{-\kappa} \beta$-cells. Genes within intersections are listed

695 in table alongside the fold-increase and significance compared to alms $1^{+/+} \beta$-cells. (E)

696 Expression of glucose response genes in si-Alms $1 \beta$-cells under basal $(2.5 \mathrm{mM})$ and high

697 glucose $(16.7 \mathrm{mM})$ conditions $(n=4)$. Cells were collected after 10 minutes after glucose

698 stimulation. Statistics, Two-Way ANOVA. (F) Relative insulin by ELISA-based detection in

699 culture media from $\beta$-cells after 30 minutes of exposure to $2.5 \mathrm{mM}$ and $16.7 \mathrm{mM}$ glucose $(n=3)$.

700 Normalized to basal si-control. Note failure of si-Alms1 cells to alter insulin secretion. Statistics,

701 Two-Way ANOVA. Where indicated, ${ }^{*} p<0.05,{ }^{* *} p<0.01$.

702

703 Fig S1. Organ defects in alms1 $1^{-/}$zebrafish.

704 (A) Zebrafish alms1 gene expression in adult fish of indicated genotype. Statistics, One-Way

705 ANOVA. (B) Total fat consumed as assessed by fluorescence per 20 larvae in alms $1^{+/+}(\mathrm{n}=6)$

706 and alms1/- $(\mathrm{n}=7)$ larvae at $7 \mathrm{dpf}$. (C) cDNA levels of Alms1 in cultured MIN6 $\beta$-cells in control

707 and si-Alms1 conditions. Statistics, two-tailed Student's t-test with Welch's Correction. Where

708 indicated, ${ }^{* * *} p<0.0001$, NS not significant. 
710 Fig S2. Significantly down-regulated genes in alms $1^{-/-} \beta$-cell enriched populations.

711 Gene Ontology (A) and ConsensusPath DB (B) analysis of significantly down-regulated genes

712 between $\beta$-cells isolated from alms $1^{+/+}$and alms $1^{-/}$zebrafish. Green highlight, incretin hormone

713 pathway nodes.

714

715 Fig S3. Significantly up-regulated genes in alms1 ${ }^{-/} \beta$-cell enriched populations.

716 Gene Ontology $(A)$ and ConsensusPath DB (B) analysis of significantly up-regulated genes

717 between $\beta$-cells isolated from alms $1^{+/+}$and alms $1^{-/}$zebrafish. Green highlight, pancreatic

718 secretion and diabetes-related pathway nodes. 
A

alms $1^{+/+}$

CTTTTGAGCTCTGGTGGTCGTTTAATCGGAGCAGATGGCTCATTCTT

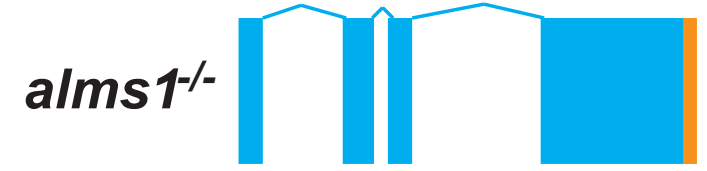

B

Genotype alms1 ${ }^{+/+}$

\begin{tabular}{l|l}
\hline alms1 $^{+-}$ & $58.89 \pm 10.19$ \\
\hline alms1 & $14.55 \pm 5.46$
\end{tabular}

\section{Incidence}

$26.56 \pm 8.89$

$58.89 \pm 10.19$

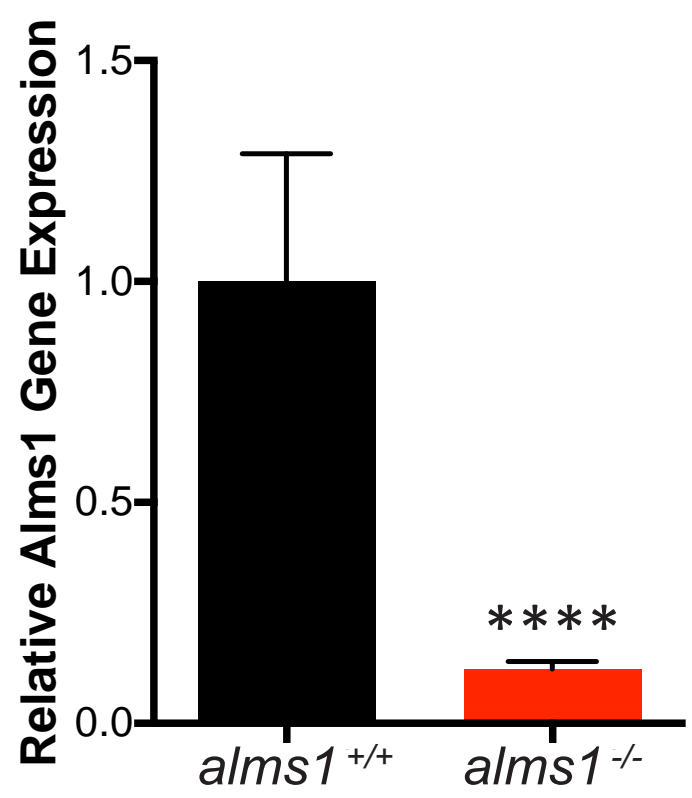

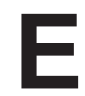

alms1

1.00 $\frac{+}{5}$

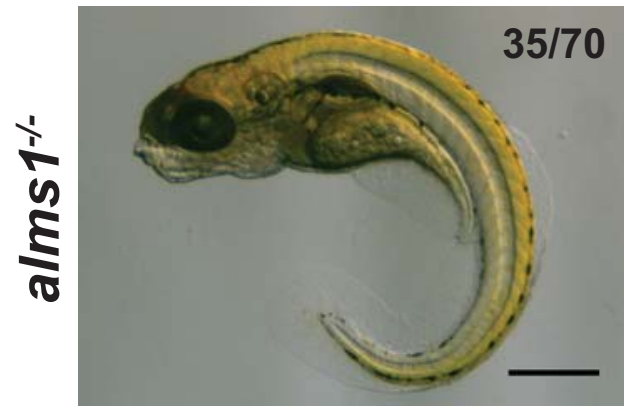

\section{$35 / 70$}

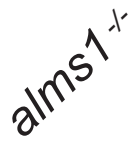

2 


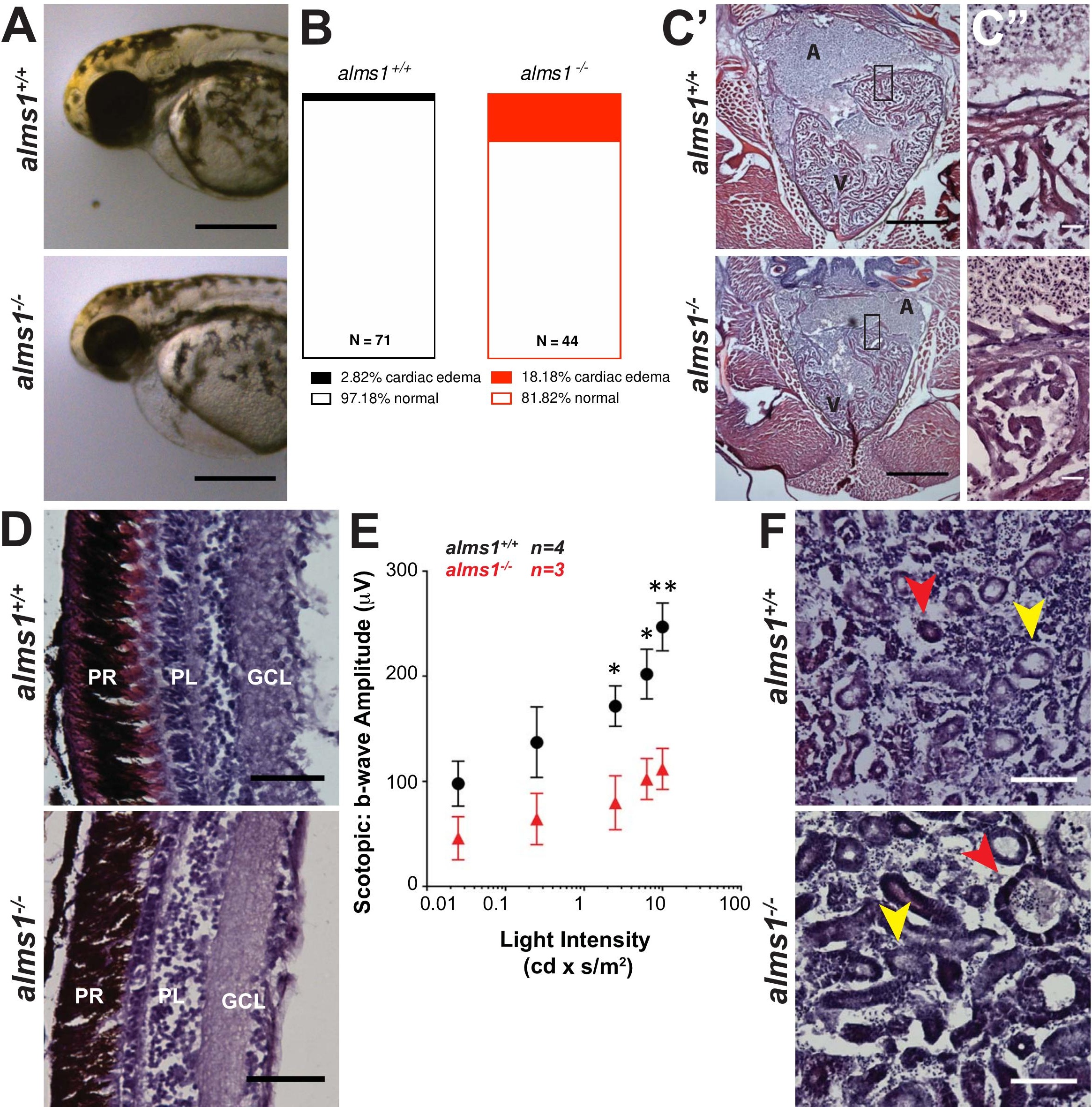

- $A l m s^{W T W T}=4$ $\Delta A l m s^{K O / K O}=3$ 
$\Delta \rightarrow$ alms $1^{+/+}$control diet $\rightarrow$ alms $1^{+/+}$high fat diet

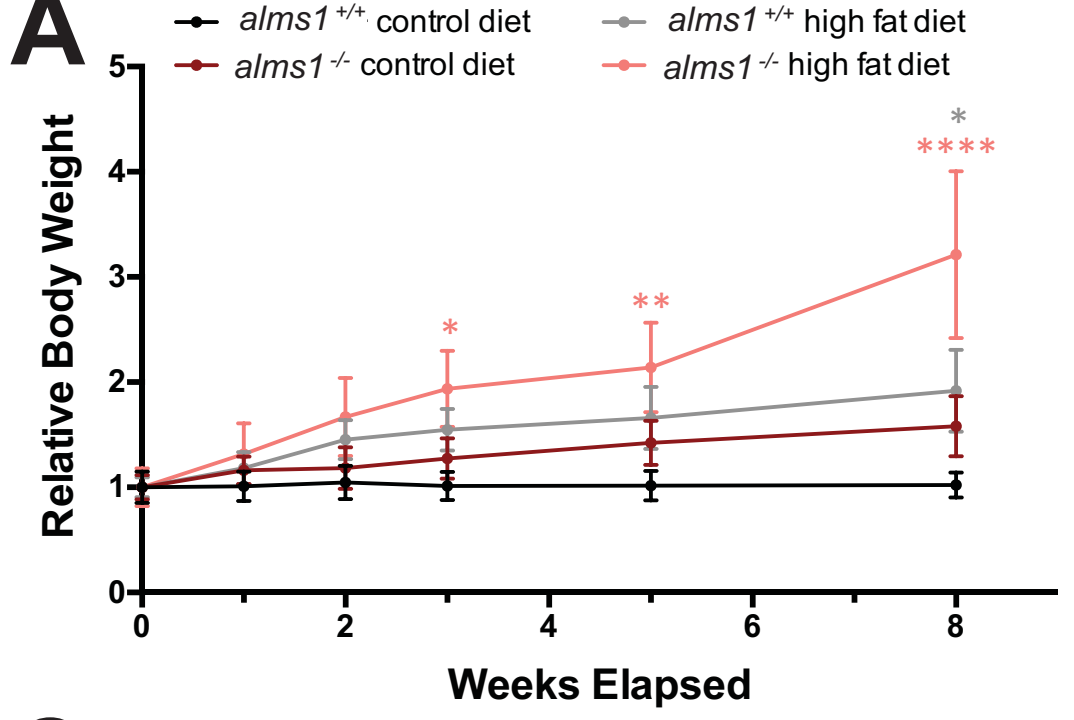

B $\quad$ alms1 $^{+/+}$

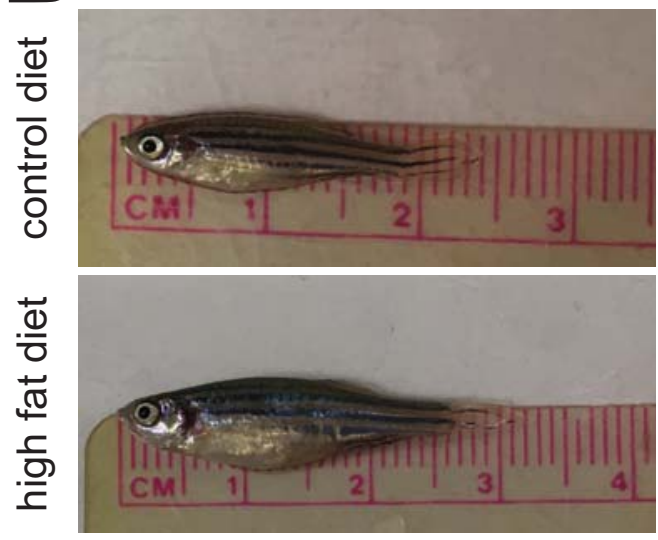

alms $1^{-/}$

$C$
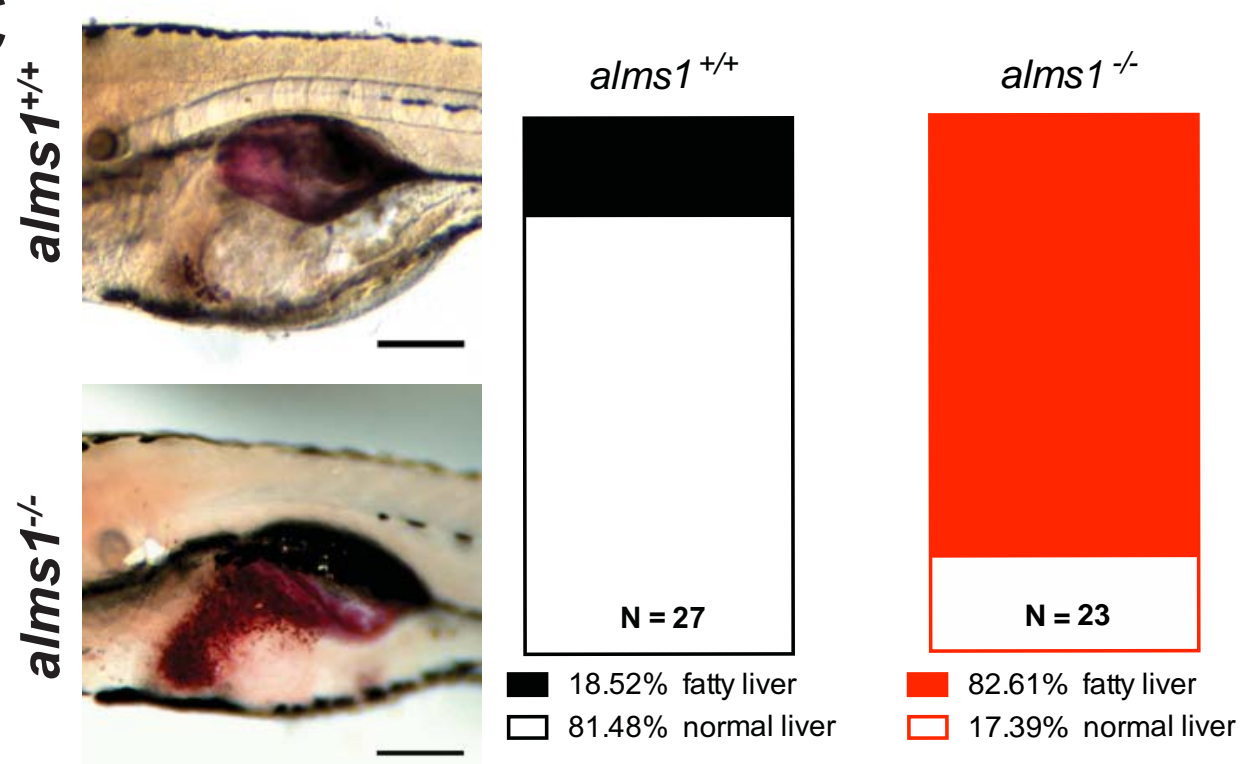

D
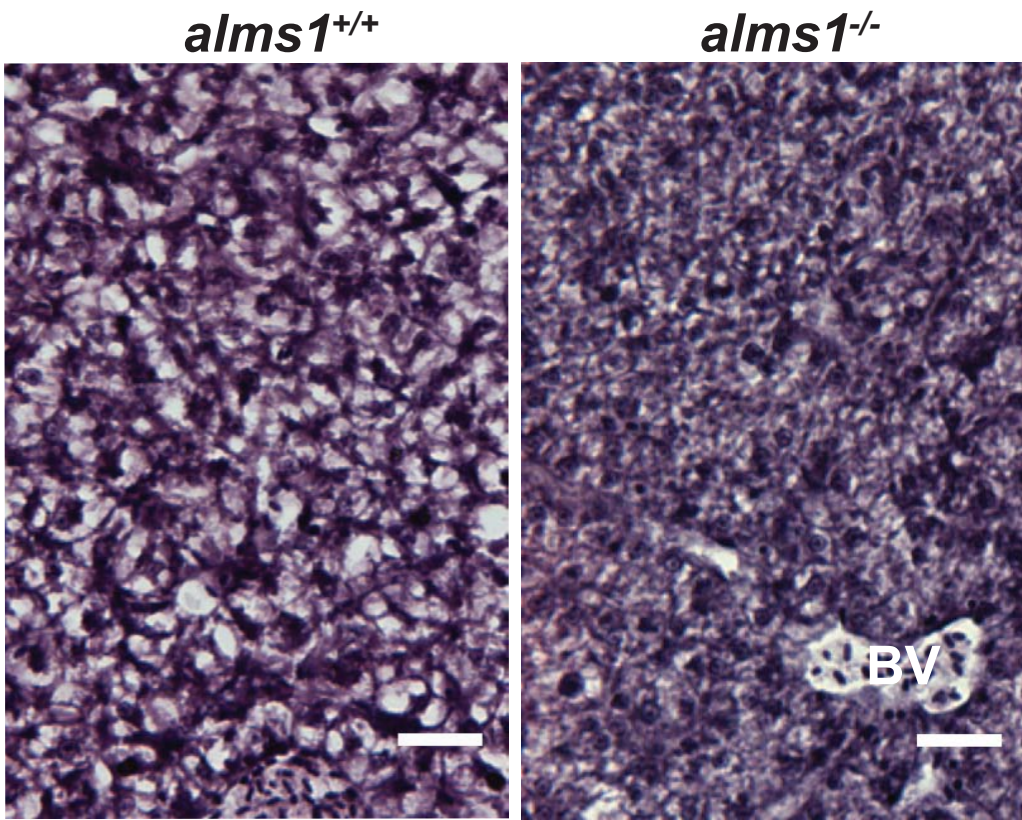

E

alms1 $1^{+/+} \quad$ alms1-/-

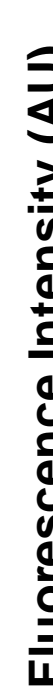

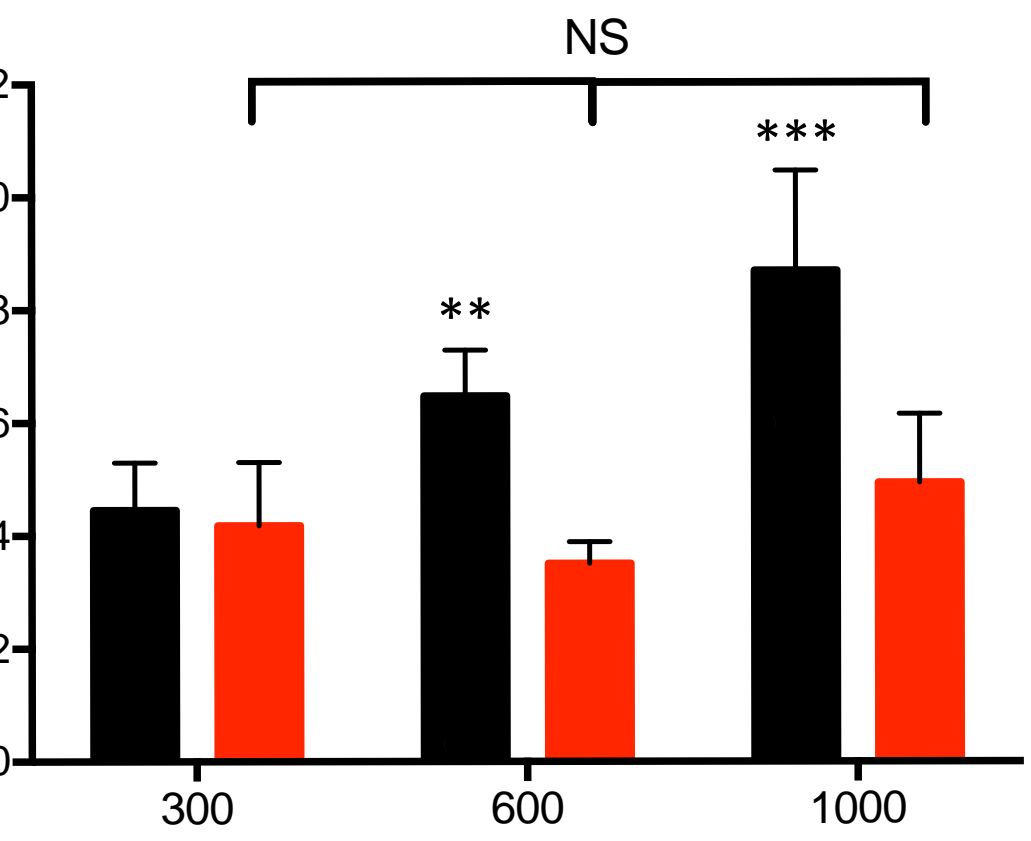

2-NBD Glucose Concentration ( $\mu \mathrm{M})$

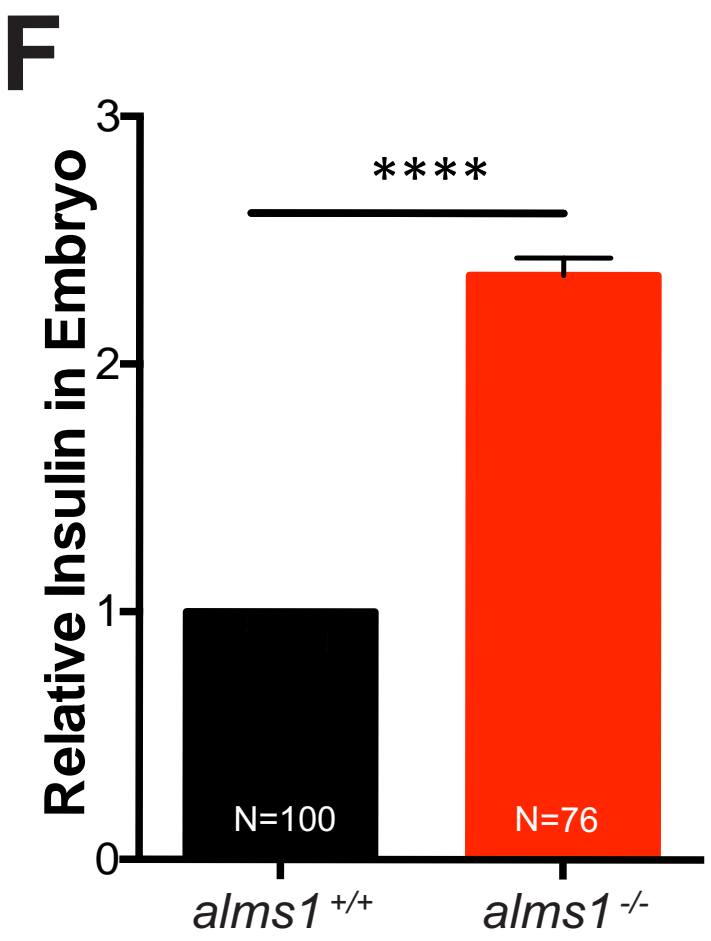


(1) morras

A $\pm$

r

$\omega$

$\frac{\xi}{\sigma}$

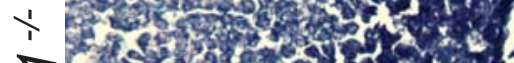

क

$\frac{\xi}{\sigma}$

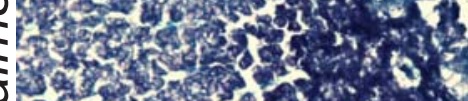
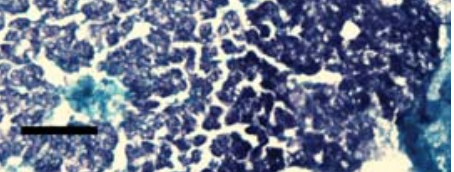

2

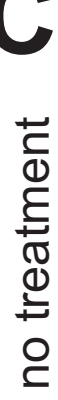

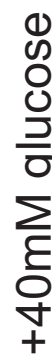

alms1+/+

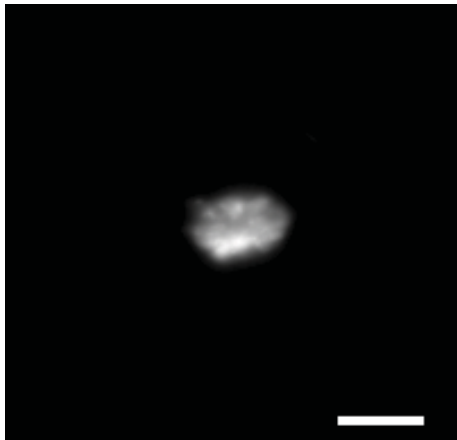

$\stackrel{+}{+}$

$\frac{5}{\frac{\pi}{\sigma}}$

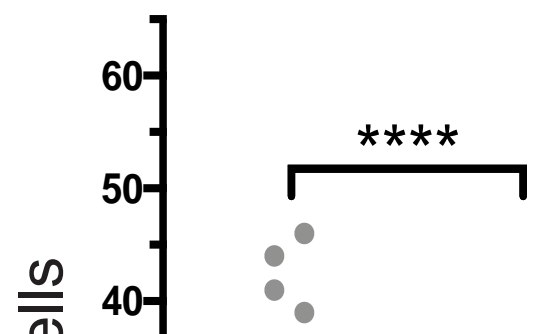

$\frac{1}{\frac{5}{\sigma}}$

$\frac{20}{\frac{20}{10}}$

a 30-

4

* 20-

$\frac{\frac{0}{0}}{\frac{0}{0}}$

10

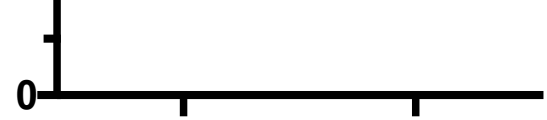

alms1 +/+ alms1--

alms 1/-

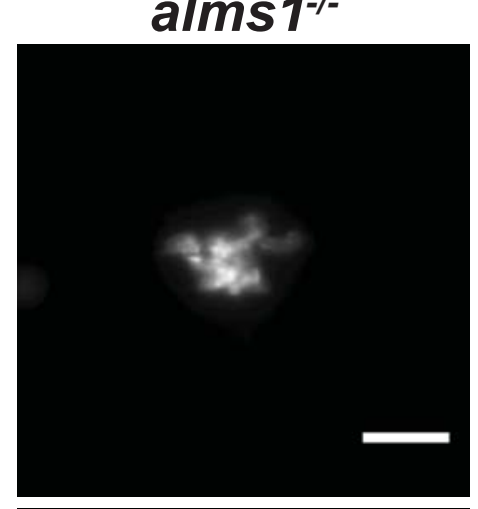

D

*
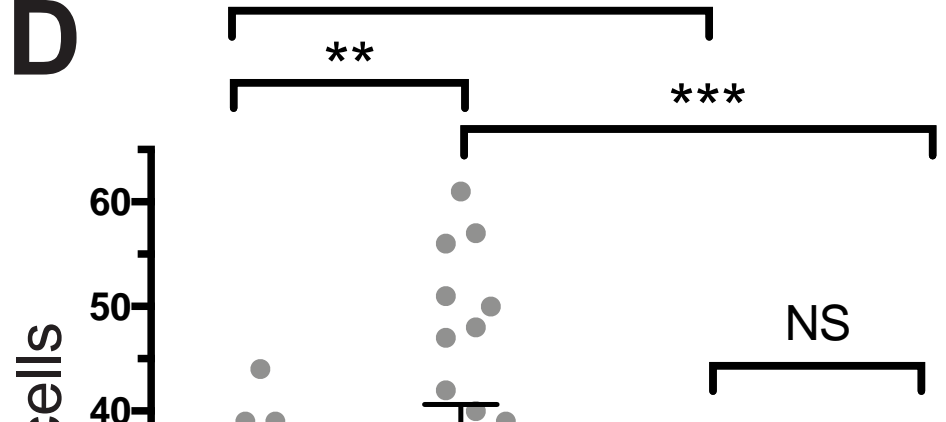

仓

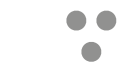

बृ

4

\# 20

$00^{\circ}$

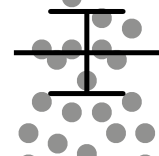

$\frac{000}{\frac{000}{600}}$

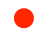

•

$\bullet$

1

$\frac{+N T+40 m M \text { glucose }}{\text { alms } 1^{+/+}} \frac{+N T+40 m M \text { glucose }}{\text { alms } 1^{-/-}}$ 
